\title{
Güncel Çin Sanat Ortamı; “Cynical Realizm”
}

\author{
Öğr. Gör. Aysun Kısaoğulları Cançat
}

\section{Öz}

$\mathrm{Bu}$ çalışmada, güncel Çin sanat ortamının; yaşanan olaylardan ve Batı dünyasından etkilenerek nasıl bir üslûp değişikliği içerisine girdiği araştırılmıştır. Çin'de yaşanan olaylar; kararsız, kimlik arayışı içinde olan, istikrarsız, stilize, ironik bir sanat üslûbunun doğmasına yol açmıştır. Bu arada, Çin'in hızla gelişen ekonomisi, Batı'nın gözünü, bu ülkeye çevirmesine neden olmuş; aynı şekilde Çin de bu ortamda sanatsal bağlamda Batı'dan yararlanmıştır. "Cynical Realizm", "Siyasi Pop" ve "Şatafatı Sanat" gibi akımlar, güncel Çin sanat ortamında ortaya çıkan akımlardan birkaçıdır. Köklü bir geçmişe sahip olan Çin sanatının, böylesine bir yön değişikliği içerisine girmesi, sanat tarihi içerisinde ilgi çekici bir gelişmedir.

Anahtar Kelimeler: Güncel Sanat, Çin Sanatı, Cynical Realizm

\section{CURRENT CHINESE ART ENVIRONMENT; “CYNICAL REALISM”}

\begin{abstract}
This study investigates how the current Chinese art environment has been affected by the incidents and the Western world and gone through a style change. The incidents in China have led to the rise of an unstable, inconsistent, stylate and ironic art style that seeks an identity. In the meantime, the rapidly growing Chinese economy has caused the West to turn towards this country and China has also started to take advantage of the West in artistic terms in this environment. Movements like "Cynical Realism", "Political Pop" and "Pompous Art" are among a few movements that have emerged in the current Chinese art environment. The fact that the Chinese art, which has a rooted background, has gone through such a change of direction is an interesting development in art history.
\end{abstract}

Keywords: Current Art, Chinese Art, Cynical Realism 
Bugünün farklılaşan sanat ortamında "Güncel Sanat" söylemi ile sıkça karşılaşılmaktadır. Sözlüklerde 'güncel'in anlamı, 'günün konusu', 'şimdiki', 'bugüne ait', 'bugünün havasına uyan' ya da 'aktüel' diye geçmektedir. Dolayısıyla, güncel sanat da günümüz ya da günümüze yakın olan sanatı ifade etmektedir. Burada bir gerçek şudur ki; şimdi/şu an güncel olan, adını ilk kez duyduğumuz bir akım ya da anlayışın da bir süre sonra güncelliğini yitireceğidir.

Günümüzde sanatçı, tüm değişik sanat şekillerinin sahibi gibidir, bir mirasçısıdır. Problem, yeni formlar icat etmektedir. Sanat formlarıyla yapılan çalışmalar ve mekânlar, değişik şekillerdedir (Bourriaud, 2008: 5). Bugünün sanatında; resim, fotoğraf, video, performans, enstalasyon gibi medium ve eğilimler birer sanat formu oluştururlar. Dolayısıyla güncel sanat; tuvali fotoğrafla, deseni videoyla, fotoğrafın üzerini desenle, desenin üzerini tekrar fotoğrafla ya da bunları farklı şekillerde birleştirmek, videosunu yapmak gibi çağdaş deneyselliklerle ele alınmaktadır.

Kopya, postprodüksyon, eğretileme ve postmodernitenin getirisi olan kavramlara/oluşumlara olanak sağlayan tüm uygulamalar ve yaklaşımlar bugünün resim sanatının beslendiği kaynaklardır. Resim, tuval üzerine boyayla uygulanan bir yüzey uygulamasından ötedir. Güncel sanatta; tüm tarihsel altyapı korunarak, ama geleneğe de kendini bağımlı hissetmeden bir demokratikleşme sürecine geçiş vardır (Saray, 2010).

Güncel sanatta; herhangi bir kısıtlama olmaksızın, ister moderne, ister çağdaşa, ister klasik döneme, isterse arkaik döneme; yani, herhangi bir döneme gönderme yapıp güncel olanı uygulama özgürlüğü vardır. Resim tarihinin silsilesine bakıldığında; yenilik, bir şeyin üzerine gelir ve bu karşıt bir şeydir; doğuşlarının gerekçeleri de budur. Bazıları uzun, bazıları kısa sürer; ama güncel sanatta, arkaik dönemden de şimdi yaşanandan da alınıp güncele uyarlanabilir (Bulut, 2014).

Günümüz sanatının bu geniş yelpazesinde, köklü ve geleneğe bağlı bir geçmişe sahip olan çağdaş Çin sanatının da teknolojik gelişmelerle harmonize edilen, kurgulanan yeni denemelerle ele alınması dikkat çekicidir. Burada hem gelenek, hem güncellik bir aradadır. Örneğin, kurgusal dijital imgeler kullanılarak sanat tarihindeki klasik eserleryeniden yaratılır; kültürel kimliği, güncel bir çevrede, yeniden algılama ve düşünme amaçlanır. Bu noktada, özellikle Çin'de etkinlik gösteren günümüz sanat akımlarında "Cynical Gerçekçilik" akımı dikkat çekicidir. Bu akım; fırtınalı, istikrarsız, belirsiz, kararsız, kimlik sorunu yaşayan bir sanat ortamının ürünüdür. Dolayısıyla akım; köklü geçmişe sahip Çin kültürüyle pek uyuşmayan ya da bu geçmişin yeniden ele alınmadığı, ama güncel olaylarla yakından ilgisi 
olan özgün özelliklere sahip bir akım olarak karşımıza çıkmaktadır.

Cynical Realizm (Müstehzi Gerçekçilik): "Cynical" kelimesinin Türkçe karşılığına bakıldığında; "müstehzi", "alaycı, "biriyle eğlenen", "insanî iyiliğe inanmayan", "küçümseyen", "toplumsal değerleri küçümseyen" gibi anlamlara gelmektedir.

Cynical realizm adı verilen bu sanat hareketi; 1990'ların başlarında, özellikle Çin'de ortaya çıkmıştır. Akımın ana teması, sosyo-politik sorunlara ve tarihi olaylara odaklanma eğilimindedir. Ayrıca akım, bugünün sanayileşme ve modernleşme çağına, Çin'in sosyolojik yanına, esprili ve post-ironik, realist bir perspektiften bakmayı hedef almıştır.

"Cynical Realizm" hareketi zamanla, Çin çağdaş sanatının önemli bir tarzı olmuştur. 1990'larda Çin çağdaş sanat ortamına "cynical realizm", "siyasi pop" ve "şatafatlı sanat" gibi akımlar eklenince, genel sanat ortamında var olan sosyal gerçekçi resim geri plana itilmiştir. ${ }^{1}$

Çin sanat ortamına bakıldığında; Çinli sanatçılar, Kültür devriminde, Rusya'da daha önce başlayan ve komünizme en uygun sanat üslûbu olarak devlet tarafından desteklenen sosyal gerçekçiliğe yönlendirilmişlerdi ve 1966-1976 arasında bu akımın içinde zorunlu olarak üretim yapmaya başlamışlardı. Ancak, Çin'de 1980'li yıllarda hızla gelişen sanat akımları ortamı oluştu. Sosyal gerçekçiliğe tepki olarak, "Cynical Gerçekçilik", 1985 'te ortaya çıkan "Yeni Dalga", "Gaudy Sanatı", "Çin Pop Sanatı" gibi akımlar birbirini izlemiştir. Pekin'de, galerilere, atölyelerin toplandığı sanatçı mahalleleri kurulmuştur. Çinli sanatçılar, geç de olsa kendi dadaist, sürrealist ve politik pop sanat akımlarını kurup sanatlarını devam ettirmişlerdir. Bu akımların yaşanması, bir anlamda, çağdaş Çin sanatının olgunlaşması için gerekliydi (Baraz, 2008). Tüm bu durumlar Çin' de sanatsal alanda yaşanan, 1979 yılında başlayan ve 1980'lerde devam eden, yeni bir dalgalanmanın olduğunu göstermektedir.

Çoğu Çin'li sanatçı, Avrupa'dakiler gibi çalışıp, sergiler gerçekleştirmeye başladılar; fakat, bu türden çalışmalar bir dönem, başarısız olarak kabul edildi ve sanatçılar sergiler için kabul edilmediler (Chen, 2007:6). Bunun yanında, Çin'de Kültür Devrimi'nin sona ermesinin ardından, sosyalist realizmin kurallarını hiçe sayan çok farklı işler de üretilmeye başlamıştı. Bunlardan bazıları dinsel temaları, bazıları Marksist bir hümanizmi, bazıları ise (1980'lerin sonunda itibaren) yeni filizlenen ve hızla yayılan tüketim kültürüyle uğraşıyordu. 
Ekonomik açıdan Batı'yla arasındaki açı̆̆ı hızla kapatan Çin'in dinamizmi, ekonomik büyüme ve dışa açılmanın sanat alanında da etkisini göstermesi, Çinli sanatçıların köklü gelenekleri üzerine, Batı'dan gelen yeni özgürlük rüzgârını kullanarak kendilerini adapte etmeleriyle ortaya çıktı. Artık çağdaş Çin sanatı, dünya müzelerinde ve sergi mekânlarında büyük ilgiyle karşılanmakta, koleksiyonlara girmekte ve eserler piyasada fahiş fiyata satılmaktaydı. Böylece Batı, Çin sanatına yatırım yapmaya başlamış, Çağdaş sanat, Çin'e döviz getiren alanlardan biri haline gelmiştir. Çin çağdaş eserlerinin yüzde 95'i yabancı alıcılar tarafından satın alınmaya başlanmış; "Cynical Realizm" ve "Siyasi Pop", Çinli sanatçıların uluslararası alanda en çok satan tarzı haline gelmiştir.

Ticaret ilişkileri, emperyalist güçlerin Çin üzerinde oynadıkları güç kavgası, 20. yüzyıldaki devrim serileri ve iç savaşlara rağmen, 19. yüzyıldan itibaren Çin, Batı resim sanatını görmeye ve tanımaya başlamıştı. 1980'lere kadar Batı resmini siyah-beyaz reprodüksiyonlardan izleyen Çinli sanatçılar, bu dönemden sonra dünya ile etkileşime geçmeye başladılar. Joseph Beuys, Andy Warhol gibi sanatçılar Çin'de etki yarattılar. Bu temasların sonucu çağdaş Çin resmi, etki ve ilhamını Batı'dan alan yeni bir yönde gelişmeye başladı. 1985-95 arası dönemin eserleri, Çin'in ilk Modern Sanat Müzesi'nde sergilenmiş̧ir. Bu dönem, Çin sanatının binlerce yıllık geçmişi olan geleneklerinden sıyrılarak, avant-garde sanat ile buluşmasını sergilemektedir. Ancak sansür, 1989 yılında sıkıyönetim ilânı ve Pekin'in Tiananmen Meydanı'ndaki katliam sonrası, hayatın her alanını olduğu gibi sanatı da etkisi altına almıştır.

1989 yılı, aslında kapitalizme kısmen açılmış Çin halkının, öğrencilerin öncülüğünde özgürlük taleplerinin sert biçimde bastırıldığı bir yıl olarak tarihe geçmiştir. Tiananmen Meydanı'nda, tanka direnen öğrenci imajı dünyanın belleğine kazınırken, sivil direnişe karşı yapılan bu kanlı bastırma eylemi ile aynı yılda, Pekin'deki Ulusal Sanat Galerisi'nde, yani devletin resmi bir sanat kurumunda "Çin/Avant-Garde" adlı bir sergi düzenlenmişti. Ancak canlı bir performans sırasında bir sanatçı, senaryosu gereği panoya ateş edince sergi, resmi yetkililer tarafından iptal edilmiştir (Baraz, 2008).

1989'da Tiananmen Meydanı'nda protestocuların katledilmesi nedeniyle küresel ilginin kısa sürede Çin sanatına yönelmesi, muhalif olarak yorumlanabilecek sanatçıların ilgi odağı haline gelmesini sağlamıştır. Dünya çapında, daha uzun vadeli bir ilgiyi kışkırtan etken ise, Çin'de kurallı piyasaların sıra dışı biçimde ortaya çıkışı, hemen ardından büyük zenginliklerin ve eşitsizliklerin belirmesi olmuştur. Ülkede, çoğu kişi için yaşam standartlarında mutedil ama hissedilir bir iyileşme gerçekleştirilmiş 
ve geniş bir tüketici kitlesi de yaratılmıştır (Stallabrass, 2009: 57).

1989 olaylarından sonra, Çin sanatı bireyselleşmeye başlamış ve uluslararası alana kaymıştır. Huang Yong Ping, Chen Zhen, Cai Guo-Qiang, Wenda $\mathrm{Gu}, \mathrm{Xu}$ Bing gibi sanatçılar ülke dışına yerleşerek, $A B D$ ve Avrupa'nın sanat merkezlerinde sergilerini açmışlardır. Bu arada, Çin'de birkaç özel galeri, Batılı ressamların çağdaş sanat eserlerini satmaya başlamıştır. illk başlarda, Çin halkına çok yabancı olan bu sanat eserleri, genellikle Çin'de yaşayan yabancılar tarafından satın alınırken; sonraları Çin'de sanata yatııı yapan zenginler, ünlü Batılı ressamların eserlerini almayı prestijlerine uygun bulmuş, Batılı olmanın bir parçası olarak görmüşlerdir.

Batı'ya açılma noktasında, Çin'de gerçekleştirilen bienaller ve trienaller de çok önemlidir. Bu aktiviteler çok yeni olmakla birlikte, 2000'li yılların başından itibaren tam uluslararası kimliğe kavuşmuşlardır. Şanghay Bienali, 2002 yılında mimari ve kent planlamacılığı temasıyla Batı dünyasının ilgisini çekmiş, ciddi tartışmalar yaratmıştır. Illk kez 2002'de yapılan Guangzhou Trienali ise, 1990-2000 yılları arasında yapılan deneysel sanat eserlerinin sunulduğu ilk organizasyonunda sanat dünyasını cezbetmiştir. $\mathrm{Bu}$ organizasyonlar Çin'i Batı'ya açarken, Çinli sanatçıların ve sanat öğrencilerinin de Batılı meslektaşların eserlerini ve ideolojilerini tanımasını sağlamıştır. Bir yandan kapitalizmin bağrından çıkıp sanatçı muhalifliğiyle sosyalizme ve sosyal başkaldırıya eğilen Batılı sanatçılar, diğer yandan komünist rejimin kısıtladığı özgürlüklerini elde etmeye çalışan Çinli sanatçılar, buluştukları noktada, piyasanın 'yeni ve taze ürün çıkarma' talebini karşılamaya çalışmaktadırlar.

Batılı sanat tarihçileri, küratör ve eleştirmenler, Batı etkileriyle ortaya konulmuş eserler için farklı yorumlar yapmaya başlamışlardır. Onlar, Çin çağdaş sanatına zaman zaman 'Batı kıyafetleri giymiş Çinli manken kız', zaman zaman da bir misyoner gibi din değiştirmesine yardımcı olduğu Asyalı muamelesi de yapmışlardır. Fransız asıllı sanat eleştirmeni Michael Nuridsany, Çin kültürünü çok iyi bilen, hem Çin'de hem de Batı'da Çin sanatı ile ilgili birçok serginin organizasyonunu yapan bir kişi olarak ve her iki tarafı da çok ayrıntılı biçimde analiz ettiği China: Art Now adlı kitabını ortaya koymuştur. Nuridsany bu kitabında, Çinli sanatçıların bazen kimlik sorunuyla karşılaştıklarını; düşüncelerini ve sanatlarındaki ifade biçimlerini Batı'nın kendilerinden beklediği biçimde şekillendirdiklerini belirtmiştir (Baraz, 2008).

Pek çok Çinli sanatçı, bu fırtınalı ve istikrarsız sanat ortamıyla yüz yüze kalmıştı. Sanatçılar için bu belirsiz sanat ortamı, sancılıydı. Yeni ve özgün ne tür çalışmalar ortaya koyacaklardı? Bu kararsız ortamda; yeni bir üslûpla 


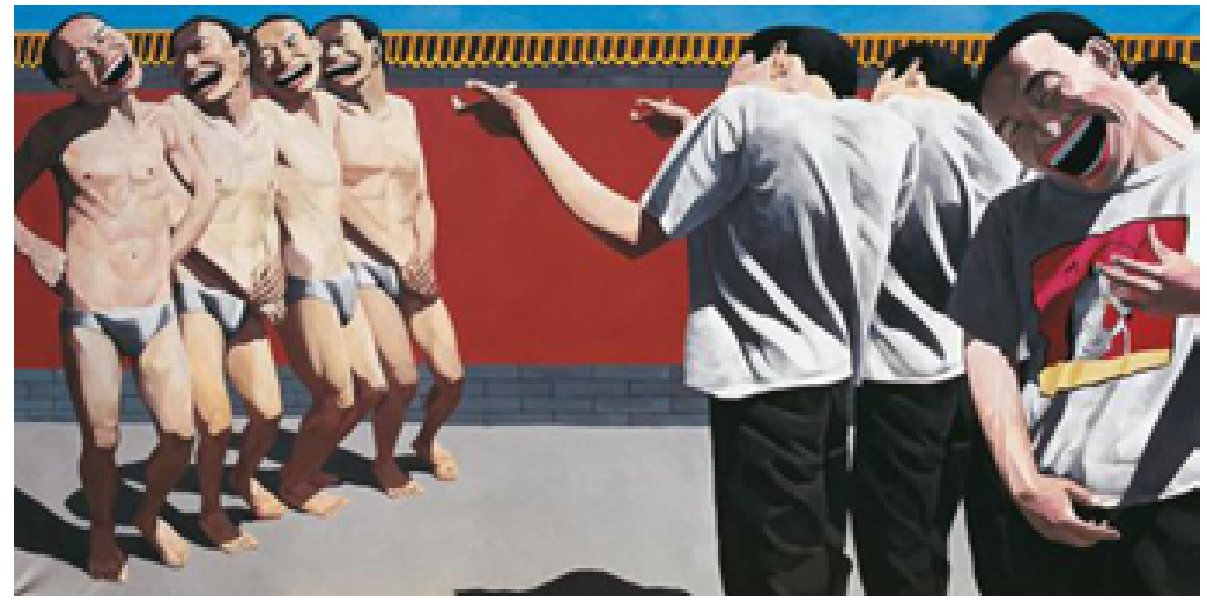

Görsel I: Yue Minjun, İdam, 1995, Tuval üzerine yağlı boya, $150 \times 300 \mathrm{~cm}$

ortaya çıkan sanatçılardan biri de Yue Minjun olmuştur.

Çin sanatının günümüze yakın bu sanat ortamında, eserlerinin üslûbu genellikle Cynical Realist olarak anılan ve bu akımın önde gelen isimlerinden olan Yue Minjun'un eserleri dikkat çekicidir. O'nun eserlerinde direkt olarak gülen portre veya portrelerle karşılaşılır. Bu gülüşler, mizahî bir durumdan mı kaynaklanmaktadır, yoksa içinde bulunulan bu belirsiz sürecin ironik bir ifadesi midir? Sanatçının resimlerinin bir diğer özelliği de poster tarzında olmasıdır. Bu poster tarzı, adeta bir kültür devriminin sosyal gerçekçi ikonografisini çağrıştırır. Minjun, ikonik figürleriyle; cinsiyet belirsizliği, sanat tarihi, sanatın manipülasyonu, çatışma ve savaş gibi çeşitli temaları ele almıştır (Li, 2002).

Minjun'un bu politik tavrı ile üslûbu, yeni ve yeniden bir ele alıştır. Öte yandan resimler, adeta pop-art etkisindedir. 1989 Tiananmen Meydanı olayları sanatçıyı derinden etkilemiştir. Bunun yanında sanatçı, üstte yer alan çalışmasında, sanat tarihinin çok önemli bir eserinden ilham almıştır: Francisco Goya'nın "3 Mayıs 1808 Asilerin Kurşuna Dizilişi". Buradaki figürler, Goya'nın, masum insanlarının kıyımının betimlendiği eserindeki figürler gibi dizilmiştir; fakat, buradaki figürlerin alaycı duruşları ve yüzlerindeki gülücükler uçurum bir fark ortaya koymaktadır. 


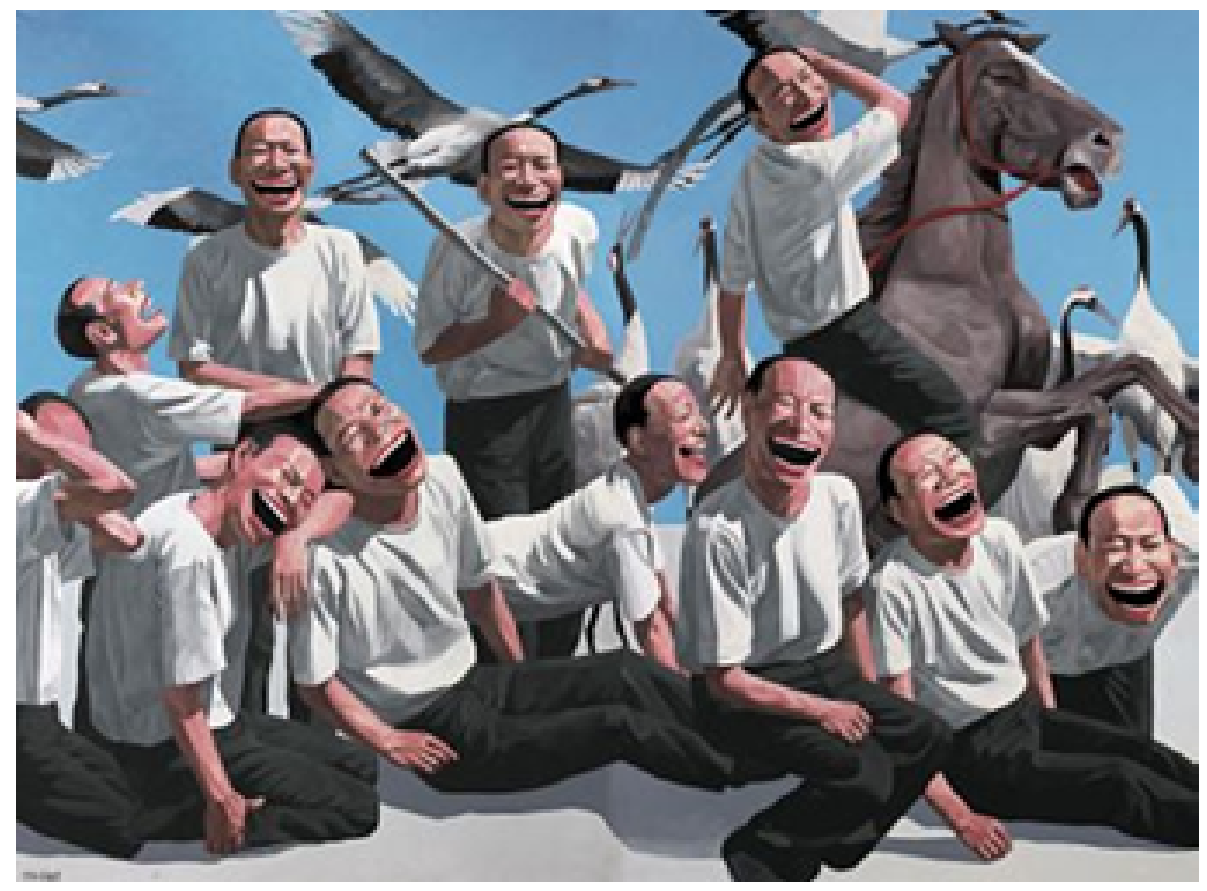

Görsel 2: Yue Minjun, Chios Katliamı, 1994, Tuval üzerine yağlı boya, 250×364 cm.

Üstte yer alan çalışmasını da sanatçı yine, Eugène Delacroix'nın Yunan tarihinden bir olayı ele aldığı 1824 tarihli çalışmasından esinlenerek yapmış ve kendine özgü üslûbuyla ortaya koymuştur. Yine bu eserdeki figürler, bir savaşa dair sahnenin yer aldığı Delacroix'nın eserindeki figürlerin duruş ve ifadelerinden çok ayrıdır.

Görüldüğü gibi, Minjun'un eserlerindeki yeniden üretim, adeta kendi ülkesiyle bir bağ kurmamızı sağlayacak niteliktedir. Sanatçı eserini, geçmişten beri süregelen savaşların, katliamların anlamsızlığını, yitirilen aklı, yine geçmişte yaşanan savaş betimlemeleriyle bir bağ kurarak ortaya koymuştur. 1989 'da gerçekleşen Tiananmen olayları da bunlardan farksızdır. Tarihteki yanılgı ve merhamet eksikliklerini yeniden kendine özgü bir şekilde ele almıştır. Tüm bunlar insanlık için utanç verici durumlardır. Sanatçı tüm bunların yanında, üslubuyla Çin hükümetine de alaycı bir dille gönderme yapmaktadır.

Cynical realist sanatçılar sadece yeniden üretim tekniğine başvurmamışlar, kendilerine uygun düşen konuları değişik üslûplarda da ele almışlardır; sürrealist, soyut ekspresyonist, çizgisel, monokrom vs. Yine Minjun'un gülen bir portreyle oluşturduğu aşağıda yer alan çalışması; sürrealist, biraz da afiş tarzında diyebileceğimiz tarzdadır. 


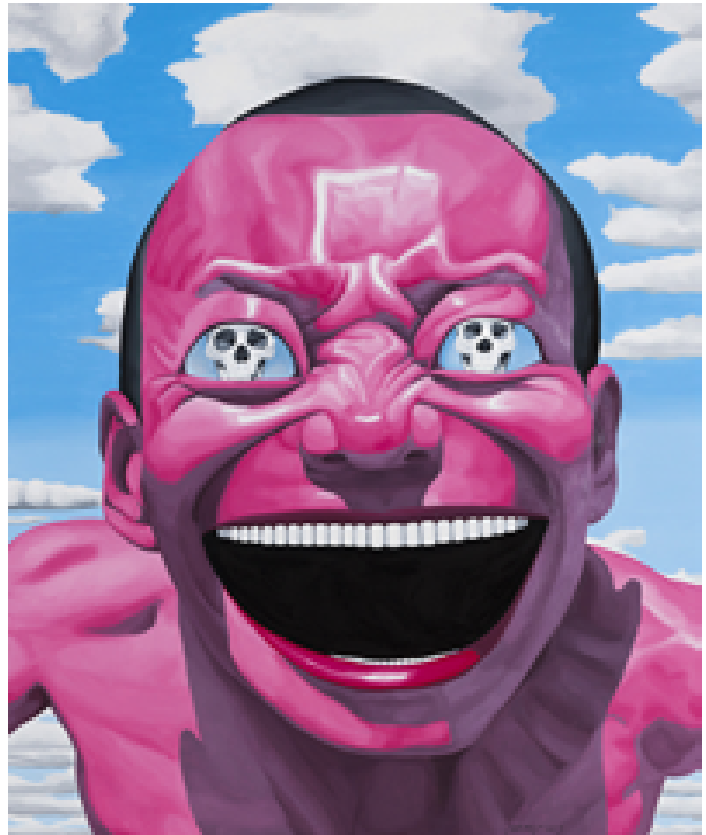

Görsel 3: Yue Minjun, Görme Yeteneği, 20I3, Tuval üzerine yağlı boya, $200 \times 240 \mathrm{~cm}$.

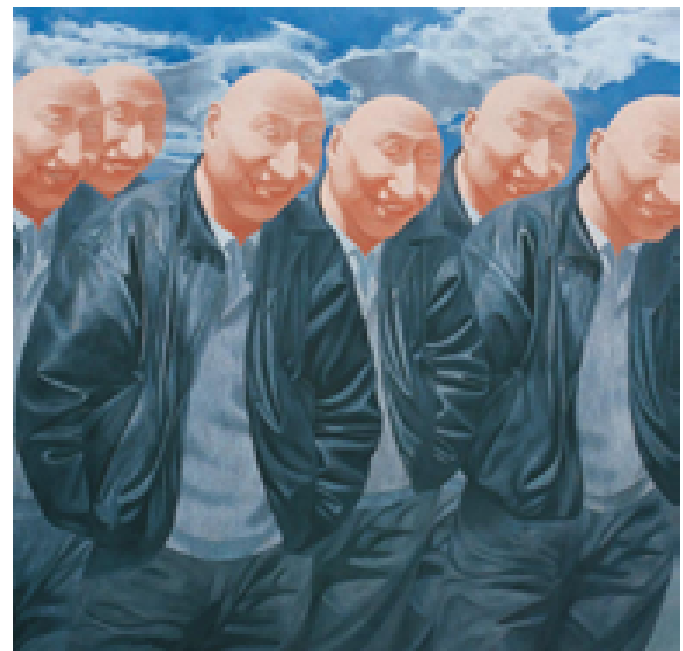

Görsel 4: Fang Lijun, Seri 02, 199I-1992, Tuval üzerine yağlı boya, 200x200 cm. 


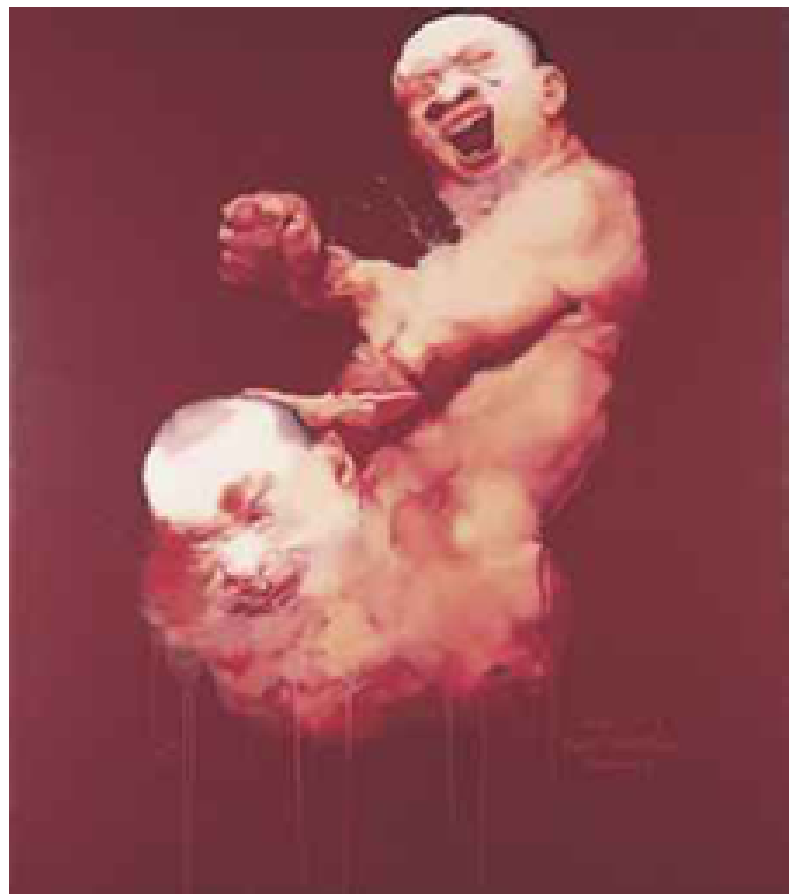

Görsel 5: Yang Shaobin, İsimsiz No.7, 200I, Tuval üzerine yağlı boya, I60x/40 cm.

Sosyal, ahlakî, insanî değerler üzerine eğilen akımın önde gelen diğer isimleri; Fang Lijun ve Yang Shaobin'dur.

Cynical realist sanatçıların bu konulara, hem kendi ülkelerinde hem de tüm dünyada yaşananlara farkındalık yaratmak adına eğildikleri ortadadır. Bu konuların; klasik eserlerden esinlenerek ve de ironik, alaycı bir tavırla yaklaşılarak ele alınması etkililiği daha da arttırmaktadır. Ayrıca, klasik eserlerin bir yeniden üretimi olan bu eserlerin pop-art üslûbuyla ortaya konması, sanatçılara dayatılan sosyal realist tarzın özgür bir açılımı olarak da değerlendirilebilir. Yeni bir dille oluşturulan bu yol, ister siyaset ister din adına hangi açıdan olursa olsun dikkat çekici olmaktadır. Başka bir amaç da unutulan Çin sanatı hakkında tekrar yankı uyandırmak da olabilir.

Bu noktada düşündürücü olan köklü bir geçmişe sahip olan Çin sanatının bu yöndeki açılımını ne zamana kadar devam ettireceğidir. Öte yandan, günümüze yakın bu oluşumda artık, talepler de göz önünde bulundurulmaktadır. Bu durum, kararsız sanat ortamını nereye sürükleyecektir? Tüm bunlar göz önüne alındığında, güncel Çin sanatının bunalım içerisinde olduğu söylenebilir. Dolayısıyla, sonraki süreçlerde ne yapılacağı önemlidir. 
Güncel sanatta, insanlığın var oluşundan itibaren her şeyi yeni veya tekrar yolu ile yeniden ele alma özgürlügü vardır. Cynical realist sanatçıların yeniden üretim (reprodüksiyon) tekniklerine yönelmiş olması, sanatçıların bu türden çalışmalarını postmodern kılmaktadır. Bu durum, daha önce var olan imgelerin aktarılmasına veya yinelenmesine olanak vermiştir. Öte yandan, özlenen klasikler günümüze, yeni bir dille çevrilmiştir. Postmodern anlayışta; sanatta çarpıştırma, yıkma, çatışmayı yaratma gibi oluşumlar, sanatı yok etme gibi anlamlara gelmemelidir. Nitekim, Çin güncel sanatındaki bu kaotik süreç, her yeni akımın ilk başlarda geçirdiği sancılı süreçler gibi yorumlanabilir ve bu durum yeni oluşumlar silsilesinin ilk filizleri olabilir. 


\section{Kaynakça}

Bourriaud, N. (2008). “Günümüzde Sanatçı.?”, (çev. Sara Hatem), Sanatartkunst Dergisi, İstanbul: Galeri Selvin Yayını.

Bulut, E. (20/4). (Marmara Üniversitesi Atatürk Eğitim Fakültesi Güzel Sanatlar Eğitimi Bölüm Başkanı) ile görüşme, Yer: Marmara Üniversitesi Atatürk Eğitim Fakültesi

Stallabrass, J. (2009). Sanat A.Ş. Çağdaş Sanat ve Bienaller (çev.Esin Soğancılar), İstanbul: Iletişim Yayınları.

\section{Internet Kaynakları}

Internet: Baraz Y. (2008). Web: http://galeribaraz.com/20/0/date/2010/08/page/2/ adresinden I 2 Mart 20I2'de alınmıştır.

Internet: Chen, K. (2007). "Çin’in Çağdaş Sanat Pazarındaki Yükselişi”s.l-I7, School of the Art Institute of Chicago Arts Organizations in Society. https:// scholar.google.co.uk/scholar?cites = I 6297862638935797 I 02 \&as_ $s d t=2005 \& s c i o d t=0,5 \& h l=$ enadresinden 12 Nisan 2012'de alınmıştır.

Internet: Li, P. (2002). Between Scylla and Charybdis: The new context of Chinese contemporary art and its creation since 2000 Web: http://www.artrealization.com/ contemporary_chinese_art/movements/cynical_realism.htm, adresinden 6 Nisan 2012'de alınmıştır.

Internet: Li, P. (-) Out ofFocus - A Dimension for Painting Web: http://www.longmarchproject. com/zlzt/pili/e-lunwen.htm adresinden 5 Mart 20I2'de alınmıştır.

Internet: Saray, Ç. (20I0). Makale: Bir Güncel Sanat Mediumu Olarak Resim ve Türkiye'de Resim Sanatı, Web: http://cagrisaray.blogspot.com.tr/2010/0I/makale-bir-guncel-sanatmediumu-olarak.html adresinden 3 Mart 2012'de alınmıştır.

\section{Görsel Kaynakları}

http://www.ft.com/cms/s/2/dI5b7a5a-23b0-I le2-a46b-00 I 44feabdc0.html\#slide0 http://www.artworldsalon.com/blog/category/asia/

http://en.cafa.com.cn/big-face-new-works-by-yue-minjun-to-be-presented-at-the-artmuseum-of-nanjing-university-of-the-arts.html

http://en.cafa.com.cn/fang-lijun-documenta-reviews-his-creations-in-singapore.html http://www.christies.com/lotfinder/paintings/yang-shaobin-55 /4734-details.aspx 
